\title{
Establishment and characterization of a novel MYC/BCL2 "double-hit" diffuse large B cell lymphoma cell line, RC
}

\author{
Lan V. Pham*, Gary Lu, Archito T. Tamayo, Juan Chen, Pramoda Challagundla, Jeffrey L. Jorgensen,
}

L. Jeffrey Medeiros and Richard J. Ford

\begin{abstract}
Background: Diffuse large B cell lymphoma (DLBCL) is the most common type of lymphoid malignancy worldwide. Approximately $5 \%$ of cases of $\mathrm{DLBCL}$ are so-called double-hit lymphomas (DHL), defined by a chromosomal translocation or rearrangement involving MYC/8q24.2 in combination with another recurrent breakpoint, usually $B C L 2 / 18 q 21.3$. Patients with MYC/BCL2 DHL are resistant to standard front-line therapy, and currently, there is no consensus for a therapeutic strategy to treat these patients. Lack of clinically relevant or validated human experimental DHL models of any type that would improve our understanding of the biologic basis of MYC/BCL2 DHL pathophysiology continues to hamper identification of valid therapeutic targets. We describe a unique MYC/BCL2 DHL cell line with morphologic features of DLBCL that we have established, designated as RC.
\end{abstract}

Methods: We used tissue culture techniques to establish the RC cell line from primary DLBCL cells. We also utilized molecular and cellular biological techniques including flow cytometry, polymerase chain reaction (PCR), DNA fingerprinting, reverse-phase protein array, conventional cytogenetics, and fluorescence in situ hybridization (FISH) analysis to characterize the RC cell line. NSG-severe combined immunodeficiency (SCID) mice were utilized as a model for xeno-transplantation of RC cells.

Results: RC cells had the following immunophenotype: positive for CD10, CD19, CD20, CD22, CD38, CD43, CD44, and CD79b and negative for CD3, CD4, CD5, CD8, CD11c, CD14, CD30, CD56, and CD200, which was identical to the primary tumor cells. Conventional cytogenetic analysis showed at(2;8)(p12;q24.2) and t(14;18)(q32;q21.3), corresponding to MYC and BCL2 gene rearrangements, respectively. DNA fingerprinting authenticated the RC cell line to be of the same clone as the primary tumor cells. In addition, RC cells were established in SCID mice as an in vivo model for translational therapeutics studies. Proteomic analysis showed activation of the mTOR signaling pathway in RC cells that can be targeted with an mTOR inhibitor.

Conclusion: The data presented confirm the validity of the RC cell line as a representative model of MYC/BCL2 DHL that will be useful for both in vitro and in vivo studies of DHL pathogenesis and therapeutics.

Keywords: Double-hit lymphoma (DHL), DLBCL, RC cell line, MYC, BCL2

\footnotetext{
* Correspondence: Ivpham@mdanderson.org

Department of Hematopathology, The University of Texas MD Anderson

Cancer Center, 1515 Holcombe Blvd. Unit 54, Houston, TX 77030, USA
} 


\section{Background}

Diffuse large B cell lymphoma (DLBCL) is the most common type of non-Hodgkin lymphoma worldwide. In the USA, DLBCL represents approximately $30 \%$ of all new lymphoma cases per year and is the fifth most common cancer [1]. Current standard front-line therapy for DLBCL patients involves rituximab immunotherapy and cyclophosphamide, doxorubicin, vincristine, and prednisone (R-CHOP). Approximately $70-80 \%$ of patients experience some form of remission, but relapsed/refractory DLBCL occurs in 30-40\% of patients within 2-3 years, and this patient subset has poor salvage therapy options [1-4].

DLBCL is a molecularly heterogeneous disease $[5,6]$. Approximately $30-40 \%$ of cases of DLBCL are characterized by recurrent chromosomal translocations involving $B C L 6 / 3 \mathrm{q} 27, B C L 2 / 18 \mathrm{q} 21.3$, and $M Y C / 8 \mathrm{q} 24.4$ in about 30, 20 , and $10 \%$ of DLBCL cases, respectively. In recent years, the concept of double-hit lymphoma (DHL) has received much attention in the literature. DHL is defined by a chromosomal breakpoint affecting the $M Y C / 8 \mathrm{q} 24.2$ locus in combination with another recurrent oncogene breakpoint, usually $B C L 2$ and less often $B C L 6$ or rarely other genes. $M Y C / B C L 2$ DHL represents approximately $70 \%$ of all cases of DHL. Double-hit lymphoma (all types) represents about $5 \%$ of all cases of DLBCL and affected patients generally have an aggressive clinical course with poor prognosis, despite combination chemotherapy, with a median overall survival less than 1-2 years [7].

To date, exploratory studies to determine the pathogenesis of DHL have been limited, in part due to the lack of a validated lymphoma cell model that is both immunophenotypically and genetically consistent with the original primary DHL tumor. To our knowledge, there have been only a small number of published manuscripts demonstrating the establishment and characterization of defined DHL cell lines. The CJ cell line that we established in 1990 before recognition of the clinical importance of DHL is believed to be the first DHL cell line showing both $M Y C$ and BCL2 gene rearrangements [8]. In 2003, we established another $M Y C / B C L 2$ DHL cell line, designated EJ-1, that morphologically resembled DLBCL [9], and recently, Hooper et al. [10] described the establishment of a novel MYC/BCL2 DHL cell line, U-2973. Several recent studies indicate that the OCI-LY18, Sc-1, and CARNAVAL DLBCL cell lines also appear to demonstrate $M Y C /$ $B C L 2$ double-hit characteristics [11, 12], but a comprehensive genetic analysis of these cell lines has not been published. Collectively, these cell lines should provide excellent models to study the pathophysiology and translational biology of $M Y C / B C L 2$ DHL. However, because these cell lines were never genetically authenticated against the primary tumor, the exact origin of these cells remains unclear. Thus, additional, validated DHL cell lines are a prerequisite for increasing our understanding and therapeutic potential of DHL.

Herein, we described the establishment and characterization of a novel $M Y C / B C L 2$ DHL cell line with morphologic features of DLBCL, designated RC, that closely shares an immunophenotype and cytogenetic features of the primary B cell tumor at diagnosis.

\section{Results}

\section{Establishment of the RC cell line}

Primary cells were obtained from a pleural effusion of a patient diagnosed with diffuse large B cell lymphoma with high-grade features (high mitotic activity and proliferation rate). The primary cells were washed, explanted, and cultured at approximately $5 \times 10^{6}$ cells $/ \mathrm{mL}$ in RPMI1640 media, supplemented with $15 \%$ fetal bovine serum (FBS) without any external stimulation. The primary cells remained viable ( 90-95\%) even after 4 weeks in cell culture; however, the number of cells remained constant. During the fifth week in culture, cell number began to increase and identifiable mitotic figures began to appear. From this timepoint, the cells doubled in number every $4-5$ days. This established lymphoma cell line successfully continued cell proliferation in a singlecell suspension without cellular clump formation, growing in continuous culture for more than 16 months, and aliquot samples could be frozen in medium composed of $90 \%$ FBS and $10 \%$ DMSO. The cell line was designated as the "RC" cell line, optimally maintained at a density between 1 and $2 \times 10^{6}$ cells $/ \mathrm{mL}$ and could be split 1:2 every 3-4 days. RC cells are medium-to-large, blastlike lymphoid cells, approximately $9-14 \mu \mathrm{m}$ in largest diameter (Fig. 1a) with moderately abundant strongly basophilic cytoplasm. The nuclei were round to ovoid with coarse chromatin and occasional irregular nuclear contours. The morphologic features of RC cells were stable and did not change during 16 months in culture (Fig. 1b).

\section{EBV status in RC cells}

The RC cells were shown to be negative for Epstein-Barr virus (EBV) by polymerase chain reaction (PCR) analysis. Epstein-Barr viral genomes (types 1 and 2) were detected in the immortalized Granta MCL cell line (positive control) but not in the MCL Mino cell lines (negative control) as expected (Fig. 1c).

\section{Immunophenotypic characterization of RC cells by flow cytometry}

We performed flow cytometry immunophenotypic analysis on the original pleural effusion sample and later on the established RC cell line after 12 months of continuous culture. The immunophenotypes of the primary tumor cells and RC cells were virtually identical 

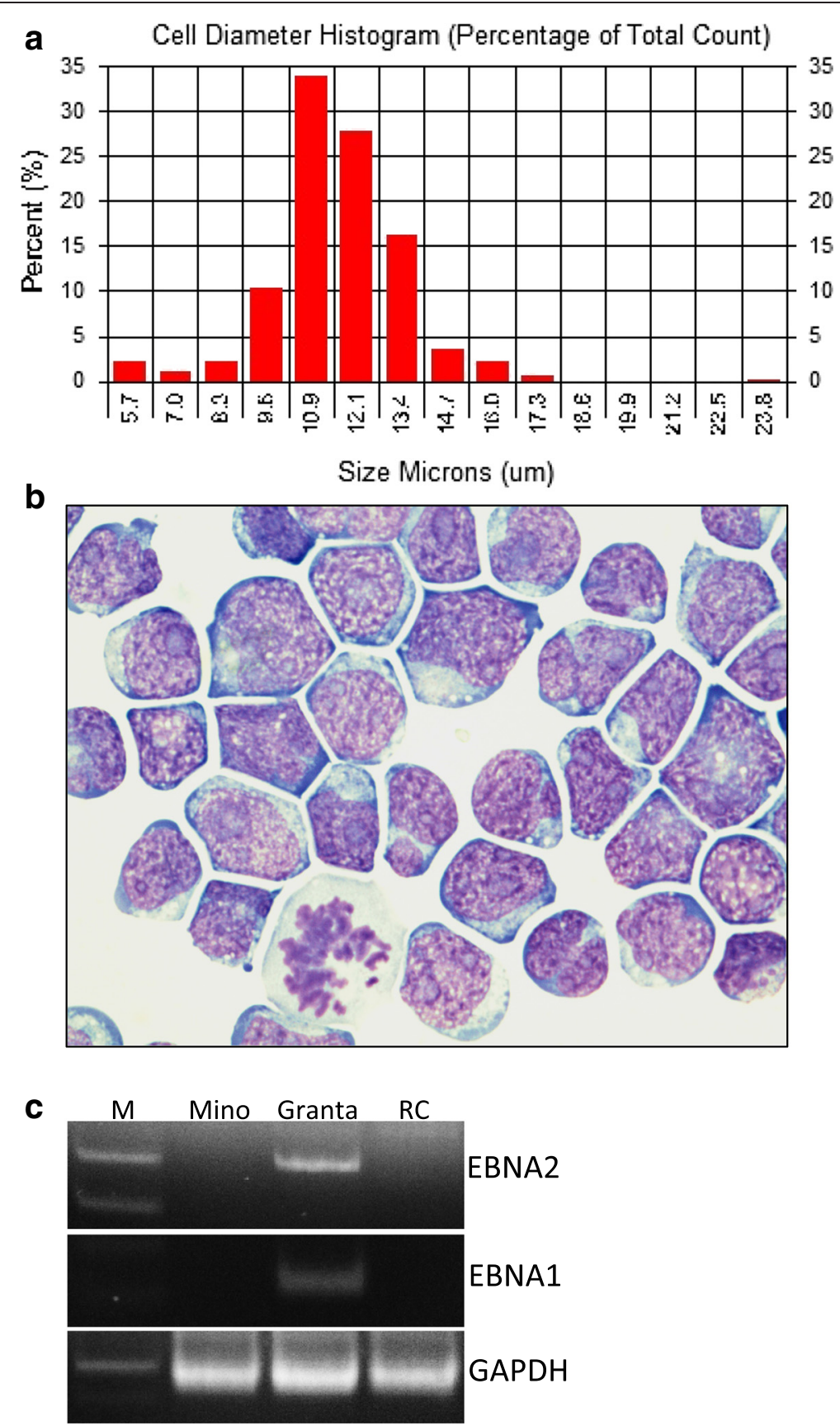

Fig. 1 Morphologic and phenotypic features of RC cells. a Distribution of the size (longest diameter) of RC cells after 16 months of cell culturing. b Representative image of H\&E-stained RC cells after 16 months in cell culture. c PCR analysis for EBV type 1 (EBNA1) and type 2 (EBNA2) gene in Mino (negative control), Granta (positive control), and RC cell lines. GAPDH serves as a loading control

(Table 1). RC cells are positive for CD10, CD19, CD20 (small subset), CD22, CD23, CD38, CD43, CD44 (partial), CD45, and CD79b and are negative for CD3, CD4, CD5, CD8, CD11c, CD14, CD30, CD200, or surface kappa and lambda light chains. Representative flow cytometry histograms showing that $99 \%$ of RC cells are positive for CD10, CD19, and CD79b, with no staining for surface kappa and lambda light chains are shown
(Fig. 2). However, the presence of surface CD79b implies surface immunoglobulin expression and therefore suggests that RC cells express an Ig light chain that was not detectable by our standard anti-kappa or anti-lambda monoclonal reagents. The original effusion cells showed no staining for CD20, possibly due to blockade by recently administered rituximab (antiCD20) therapy. The RC cell line showed very dim 
Table 1 Immunophenotype profile of primary DH-DLBCL cells and RC cells as determined by flow cytometry

\begin{tabular}{lll}
\hline Phenotype & Primary cells & RC cells \\
\hline CD5 & - & - \\
CD10 & + & + \\
CD19 & + & + \\
CD20 & - & $+/-$ \\
Kappa light chain & - & - \\
Lambda light chain & - & - \\
CD79b & + & + \\
CD23 & + & + \\
CD43 & + & + \\
CD44 & $+/-$ & $+/-$ \\
CD45 & + & + \\
CD11c & - & - \\
CD200 & - & - \\
CD22 & + & + \\
CD3 & - & - \\
CD4 & - & - \\
CD8 & - & - \\
CD14 & - & - \\
CD30 & - & - \\
\hline
\end{tabular}

- negative staining, + positive staining, $+/-\operatorname{dim} /$ partial staining

expression of CD20 (compared with normal mature B cells), possibly due to selection of primary lymphoma cells with low expression. Alternatively, dim or absent CD20 expression has been reported in cases of DHL by others [13]. RC cells also express a high level of CD38, an indicator of MYC rearrangement [14].

\section{Conventional cytogenetics and FISH analysis}

Conventional cytogenetic analysis of $\mathrm{RC}$ cells revealed a complex karyotype, including a $\mathrm{t}(2 ; 8)(\mathrm{p} 12 ; \mathrm{q} 24.2)$ and a $t(14 ; 18)$ (q32; 21.3 ) (Fig. 3a). The karyotype of $R C$ cells is similar to, but more complex than, the karyotype of the primary lymphoma cells (Table 2). However, only 15 metaphases were available for analysis of the primary tumor cells. Interphase fluorescence in situ hybridization (FISH) analysis with FISH mapback performed on the RC cells showed multiple copies of $I G H / B C L 2$ fusion gene (Fig. 3b) and an allelic $M Y C$ rearrangement most likely involving the $I G K$ gene mapped to 2p12 region (Fig. 3c) and corroborating the $\mathrm{t}(2 ; 8)(\mathrm{p} 12 ; \mathrm{q} 24.2)$ identified by conventional cytogenetic analysis (Fig. 3a). RC cells were negative for $I G H / M Y C$ and IGH/CCND1 fusions as assessed by FISH (data not shown).

\section{STR DNA fingerprinting analysis of primary cells and RC cells}

Using a multiplex short tandem repeat (STR) DNA fingerprinting system, which allows for the detection of unique DNA fingerprints through the genotyping of 16 STR loci, primary lymphoma cells and the RC cells shared $100 \%$ identity. These results confirm that the genetic parentage of RC cells is, in fact, the patient's lymphoma cells (Table 3 ). The $\mathrm{RC}$ cell line profile did not match any other cell line profile in the current database at MD Anderson Cancer Center or elsewhere.

\section{Xeno-transplantation of RC cells into SCID mice}

We inoculated RC cells by intraperitoneal (IP) injection into the lower abdomen of five severe combined immunodeficiency (SCID) mice. Within 5 weeks, all five (100 \%) mice developed a solid tumor mass in the lower abdomen (Fig. 4a). Further analysis showed that the excised tumor mass was composed of lymphoid cells (Fig. 4b) of human B cell origin, CD20 positive with characteristic CD20 cell membranous expression (Fig. 4c), morphologically consistent with RC cells.

\section{Reverse-phase protein array (RPPA) analysis and response to an mTOR inhibitor}

We performed RPPA analysis on the RC cell line and three additional DLBCL cell lines to determine the protein signaling profile of RC cell line. After quality control analysis, expression data for 285 proteins were available for further analysis. Supervised hierarchical clustering of the data for all proteins showed a set of up-regulated and down-regulated proteins in the $\mathrm{RC}$ cell line that differed from the other three DLBCL cell lines (Fig. 5a). Based on the RPPA data, a diagram model was constructed showing activation of the integrin-MEK-ELK1 and the insulin-AKT-mTOR signaling pathways as being used prominently in RC cells (Fig. 5b).

We also used a small molecule inhibitor of mTOR (AZD8055) to determine whether RC cells can respond to this agent. As demonstrated in Fig. 6a, RC cells are highly sensitive to AZD8055 in comparison to the other three DLBCL cell lines. In addition, RC cells treated with AZD8055 down-regulate protein expression of phosphorAKT and phosphor-mTOR that are low or absent in AZD8055-resistant MZ cells (Fig. 6b). These findings indicate that the RC cell line is an excellent model for identifying potential therapeutic agents, targeting pathways like the PI3K-ATK-mTOR survival pathway.

\section{Discussion}

Although others had reported cases of DLBCL with $M Y C$ and BCL2 rearrangements previously [17-20], Aukema and colleagues [16] in 2011 published an important review article that introduced the concept of 

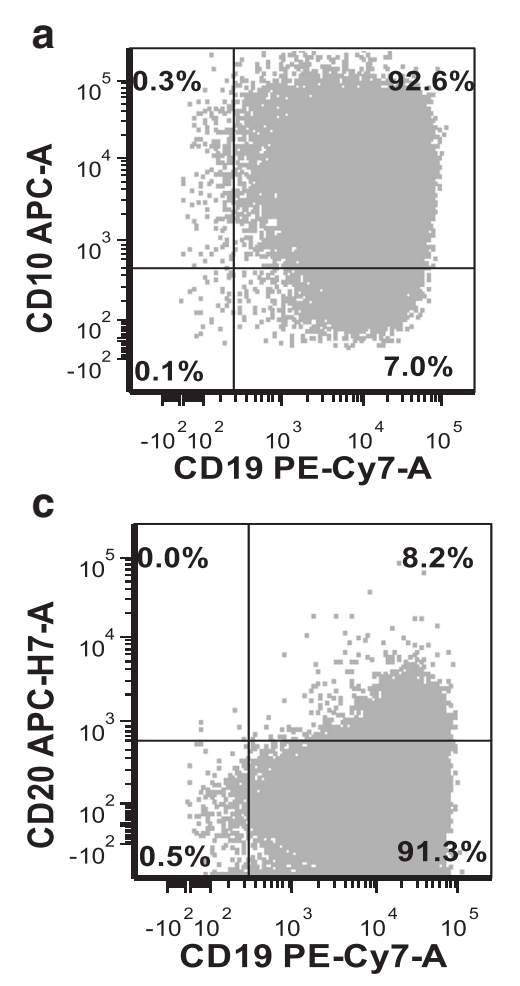

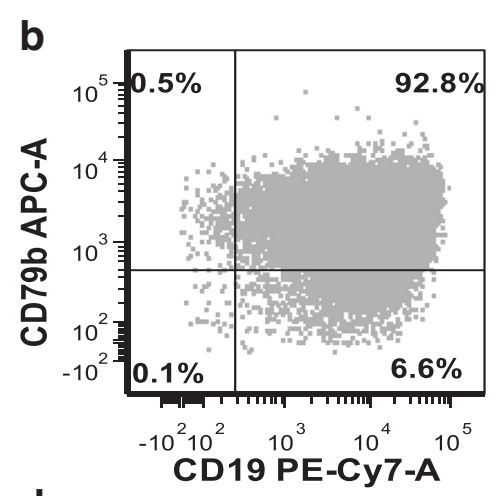

d

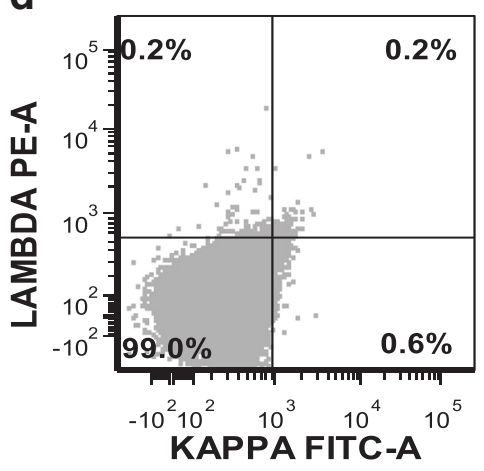

Fig. 2 Immunophenotype of RC cells. Representative flow cytometric histograms of total RC cells. a RC cells are positive for CD19 and CD10; b they are positive for CD79b, implying surface immunoglobulin expression; $\mathbf{c}$ they are positive for CD20 in only a small subset; $\mathbf{d}$ they stained negative for both surface kappa and lambda lg light chains

DHL. Aukema and colleagues defined DHL as a neoplasm characterized by a $M Y C$ rearrangement combined with another genetic abnormality, such as $B C L 2, B C L 3$, $B C L 6$, or other genes. Currently, over 400 cases of DHL have been reported in the literature, with the combination of $M Y C$ and BCL2 being, by far, the most common. These studies have shown that patients with double-hit lymphoma associated with $M Y C / 8 \mathrm{q} 24.2$ and $I G H-B C L 2 / t(14 ; 18)$ have an aggressive disease, clinically characterized by $\mathrm{B}$ type symptoms, advanced clinical stage, a high International prognostic index (IPI), poor response to standard front-line $\mathrm{R}-\mathrm{CHOP}$ or more aggressive therapies, and a very poor prognosis with a median survival of $1-2$ years $[7,21]$. As a result of the poor prognosis, DHL is currently a subject of intense clinical and research interest because there is no consensus therapeutic approach for these patients and the conceptual/mechanistic basis underlying the DHL remains unclear [15].

A major limitation to the successful treatment of patients with $M Y C / B C L 2$ DHL is an improved understanding of disease pathogenesis, mechanisms of chemotherapeutic resistance, and knowledge of potential therapeutic targets for which new therapies can be rationally designed. We suggest that the RC cell line reported here is of interest and will be a useful tool that will be helpful in contributing to an improved understanding of $M Y C / B C L 2$ DHL. The RC cell line has the advantage of having been well studied initially, with further relevant follow-up studies. Its derivation from a patient with a DHL is clearly identified by STR analysis. The RC cells have usual morphologic features of DLBCL and the $M Y C$ and BCL2 abnormalities are well documented by conventional cytogenetic analysis and fluorescence in situ hybridization (FISH). The MYC rearrangement involves $I G K$ gene mapped at $2 \mathrm{p} 12$ region corroborating the $\mathrm{t}(2 ; 8)(\mathrm{p} 12 ; \mathrm{q} 24.2)$ identified by constitutional cytogenetic analysis. RC cells have a germinal center B cell immunophenotype, as is the case for almost all published cases of $M Y C / B C L 2 \mathrm{DHL}$, and a complete immunophenotype is shown by flow cytometry immunophenotypic analysis. Similar to the original lymphoma cells, RC cells showed dim/low CD20 expression. The molecular mechanism(s) resulting in decreased expression of CD20 in RC cells and in DHL are unclear and have not been explored [13]. The decreased expression of CD20 in DHL suggests that the use of second-generation monoclonal antibodies targeting CD20 may be fruitful because these engineered antibodies are reportedly more effective than rituximab in inducing complement-dependent cytotoxicity, particularly in tumors with decreased CD20 antigen density [22, 23].

Several general findings have emerged from recently published DHL retrospective series [7]. These studies 


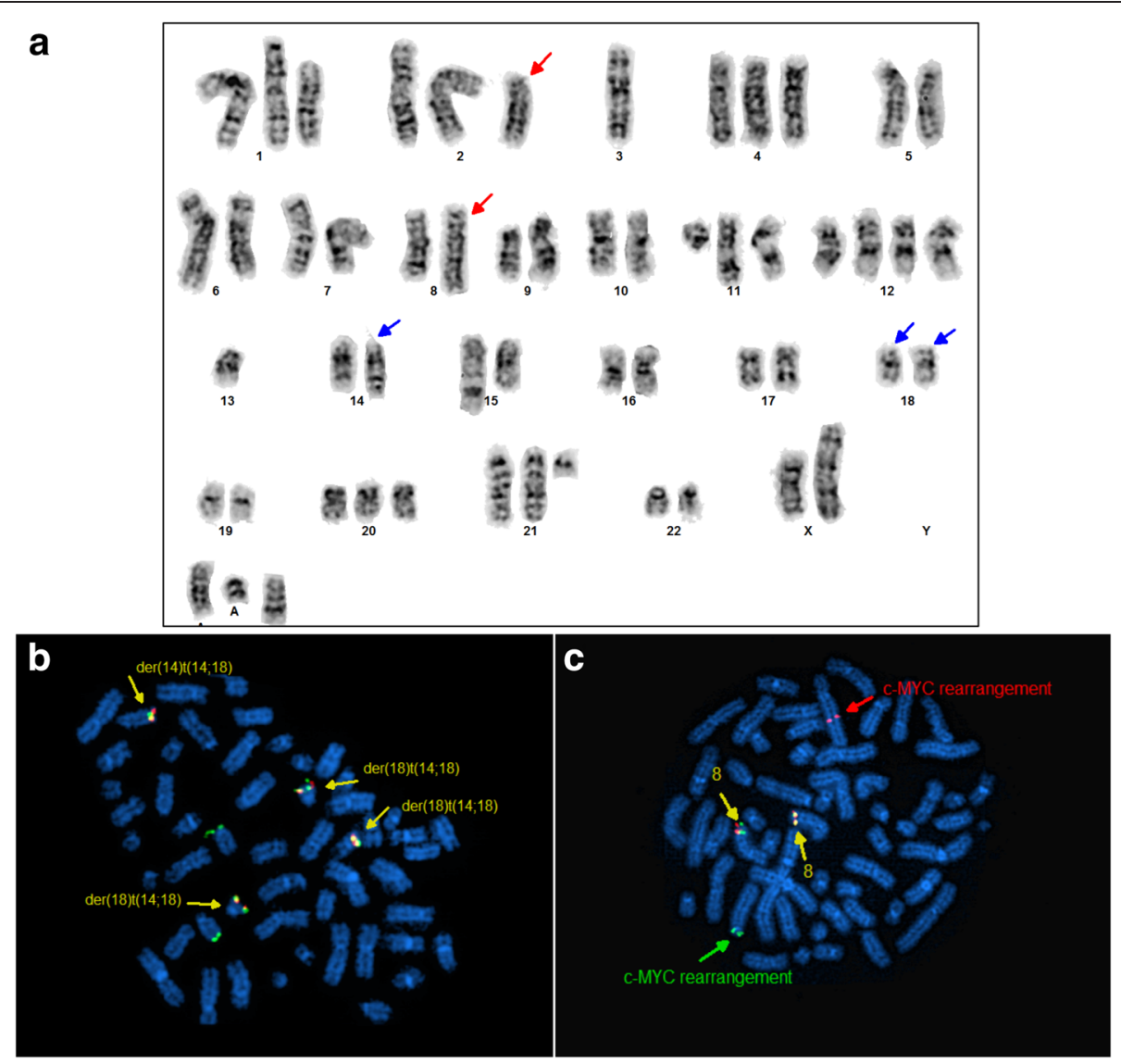

Fig. 3 Conventional cytogenetics and FISH analysis of RC cells. a Representative karyotype of RC cells. Red arrows point to $t(2 ; 8)(p 12 ; q 24.2)$ translocation, and blue arrows point to $\mathrm{t}(14 ; 18)(\mathrm{q} 32 ; \mathrm{q} 21.3)$ translocation also showing an extra copy of der(18)t(14;18) in the karyotype. $\mathbf{b}$ FISH analysis confirmed $\mathrm{t}(14 ; 18)$ in RC cells. IGH/BCL2 dual-color, dual-fusion translocation probes were used. Green: probe for the immunoglobulin heavy chain gene; red: probe for the BCL2 gene; yellow: IGH-BCL2 fusion gene signal. c FISH analysis of MYC gene rearrangement, showing one red and one green on the $\operatorname{der}(8) t(2 ; 8)$ and $\operatorname{der}(2) t(2 ; 8)$, respectively

show that patients with DHL often present with extranodal disease, central nervous system (CNS) involvement is more common, and higher international prognostic index (IPI) scores. However, retrospective studies have not been able to contribute to a deeper understanding of DHL or provide clues to potential therapeutic targets that would enable substantial progress in therapy. Using RPPA analysis, we have identified at least two important growth/survival pathways (integrin-MEK-ELK1 and the insulin-AKT-mTOR) that are highly activated in RC cells. RC cells are highly sensitive to small molecule inhibitors of the AKT-mTOR pathway. Although it has already been shown that the PI3K/Akt/mTOR pathway is highly active in many B cell malignancies, including DLBCL [24], our study is the first to demonstrate the activation of these growth/survival pathways in a representative DHL-DLBCL cell line. However, a recent study showed that the PI3K/mTOR inhibitor BEZ235 can potentiate the activity of the HDAC inhibitor panobinostat in pre-clinical models of DLBCL, including DHL cell lines with overexpression of bcl-2 and MYC [12], further suggesting activation of Akt/mTOR activation in DHL. Further studies in more DHL cell lines as well as primary cells are required to validate whether the integrin-

Table 2 Clonal cytogenetic abnormalities in lymphoma cells from primary bone marrow sample and from RC cell line

\begin{tabular}{|c|c|}
\hline Karyotype & \\
\hline Primary cells & RC cell line \\
\hline $\begin{array}{l}45 \sim 56, X, \operatorname{der}(X) t(X ; 3)(p 22.1 ; p 13),+1, \text { add }(1)(p 32), i(1)(q 10),- \\
3, \operatorname{del}(3)(p 13 p 25), a d d(6)(q 23),+7, \operatorname{der}(8) \\
\text { (2;8)(p12;q24.2),t(11;15)(q13;q26),+12,t(14;18) } \\
(q 32 ; q 21.3),+21,+2 \sim 6 m a r[c p 9] / 46, X X[6]\end{array}$ & $\begin{array}{l}\text { 45 56,X,der(X)t(X;3)(p22.1; } 13),+1, \text { add }(1)(p 32), \operatorname{del}(1)(\mathrm{p} 34.3 \mathrm{p} 36.1), \mathrm{t}(2 ; 8) \\
(\mathrm{p} 12 ; \mathrm{q} 24.2),-3,+4, \operatorname{add}(6)(\mathrm{q} 23),+8,+11, \mathrm{t}(11 ; 15)(\mathrm{q} 13 ; \mathrm{q} 26),+12,+12,-13, \\
\operatorname{add}(13)(\mathrm{q} 34), \mathrm{t}(14 ; 18)(\mathrm{q} 32 ; \mathrm{q} 21.3),+\operatorname{der}(18) \mathrm{t}(14 ; 18) \times 1 \sim 2,+20,+21, \mathrm{psu} \\
\operatorname{dic}(21 ; 1)(\mathrm{q} 22 ; \mathrm{p} 13) \times 2,+2 \sim 4 \mathrm{mar}[\mathrm{cp} 20]\end{array}$ \\
\hline
\end{tabular}


Table 3 STR DNA fingerprinting of primary cells and RC cells

\begin{tabular}{|c|c|c|c|c|c|c|c|c|}
\hline \multirow[t]{2}{*}{ Sample } & \multicolumn{8}{|c|}{ STR Loci } \\
\hline & AMEL & CSF1PO & D13S317 & D16S539 & D21S11 & FGA & THO1 & TPOX \\
\hline Primary cells & $X, Y$ & 10,12 & 12 & 11 & $28,32.2$ & 21,24 & $9,9.3$ & 8,11 \\
\hline RC cells & $X, Y$ & 10,12 & 12 & 11 & $28,32.2$ & 21,24 & $9,9.3$ & 8,11 \\
\hline
\end{tabular}

MEK-ELK1 and the insulin-AKT-mTOR pathways are commonly activated and can be targeted in DHL. Targeting the $\mathrm{PI} 3 \mathrm{~K} / \mathrm{mTOR}$ pathway as was shown in this study is just one example of the utility of the RC cell line in biomarker research and drug development. New drugs, particularly targeted therapeutic agents [25-27], are increasingly being developed and entered the clinic in recent years. Therefore, a fully characterized $M Y C /$ BCL2 DHL cell line with morphologic features of DLBCL, like RC, will be valuable for researchers in identifying novel targets and pre-clinical screening studies of novel therapies that potentially can benefit patients [28].

Although not a specific focus of this study, it seems that the concept of DHL has some limitations. It appears likely that disease and resistance mechanisms in $M Y C /$ BCL2 DHL are likely to differ from $M Y C / B C L 6$ DHL and therefore the designation of DHL is descriptive but not sufficiently specific. Even with the most common $M Y C / B C L 2$ DHL, one of our early cell lines, CJ, was derived from an elderly woman with typical low-grade follicular lymphoma, with the usual $t(14: 18)(\mathrm{q} 32 ; \mathrm{q} 21.3)$ who was initially successfully treated with conventional CHOP chemotherapy, achieving a remission lasting several years. This patient subsequently relapsed with aggressive $M Y C / B C L 2$ DHL with a complex karyotype and multiple other uncharacterized cytogenetic abnormalities. Interestingly, this DHL did not show the expected DLBCL morphology but retained the grade 1 (centrocytic or small cleaved cell) morphology [7], while clearly progressing from indolent to aggressive phenotype both in vitro and in vivo (SCID XT). CJ cells are not only DHL cells but also currently the only known centrocytic cell line, with a unique pathophysiology, suggesting that $M Y C / B C L 2$ DHL is heterogeneous and may provide insights into pathophysiologic mechanisms such as large cell transformation of follicular lymphoma. Although we believe the $\mathrm{RC}$ cell line will be an excellent experimental tool to study $M Y C / B C L 2$ double-hit lymphoma, other additional cell lines, for example to study $M Y C / B C L 6$ double-hit lymphomas, will also be needed to better understand these less common DHL tumors.

In summary, in this study, we report the establishment and characterization of a novel $M Y C / B C L 2$ DHL cell line with morphologic features of DLBCL, RC, that immunophenotypically and cytogenetically closely resembles the
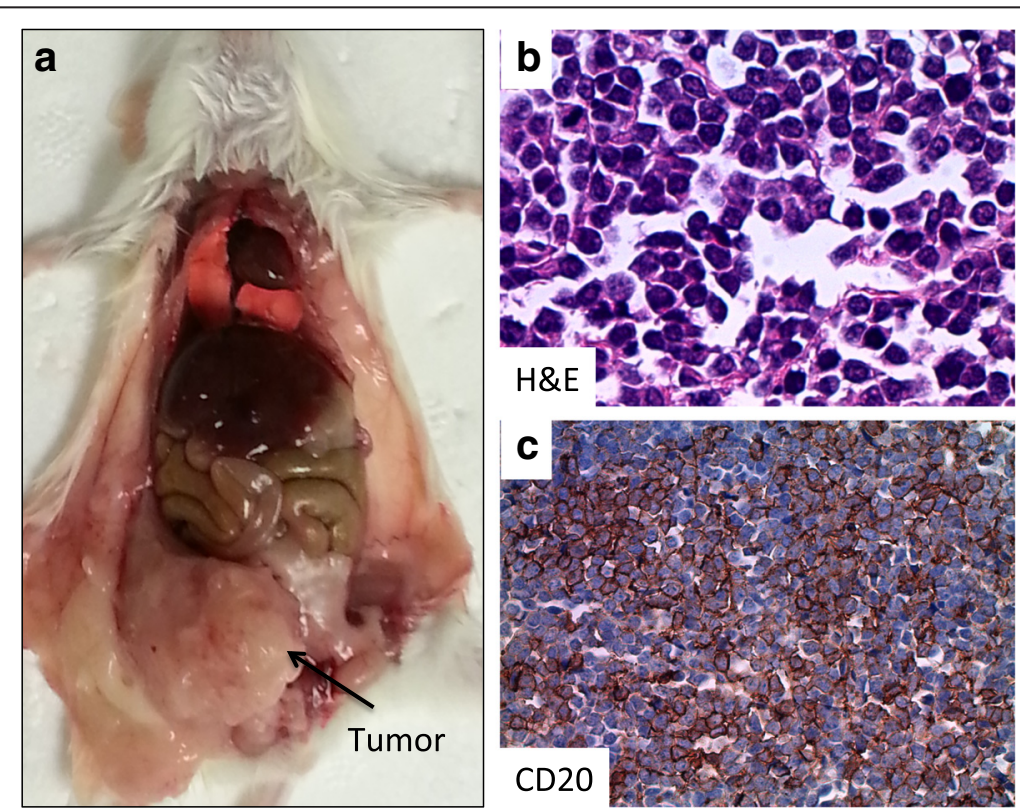

Fig. 4 Xeno-transplantation of RC cells into SCID mice. a Necropsy of a SCID mouse that received a transplant of RC cells. Arrow pointing to the tumor mass. b H\&E paraffin sections of the SCID peritoneal tumor bearing the RC tumor cells. $\mathbf{c}$ Immunohistochemical analysis of the transplanted lymphoma from a SCID mouse showing the expression of CD20 
a

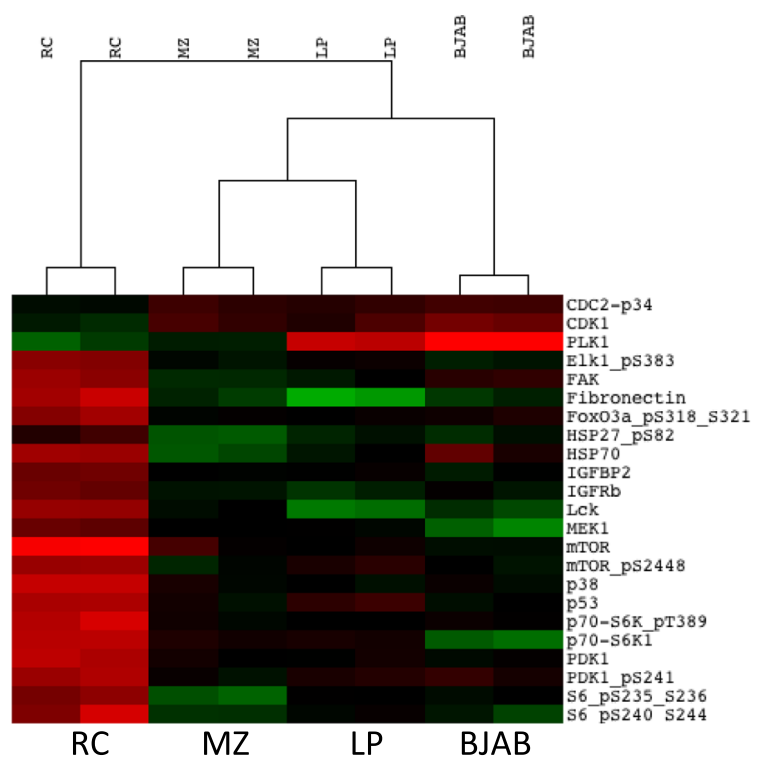

b

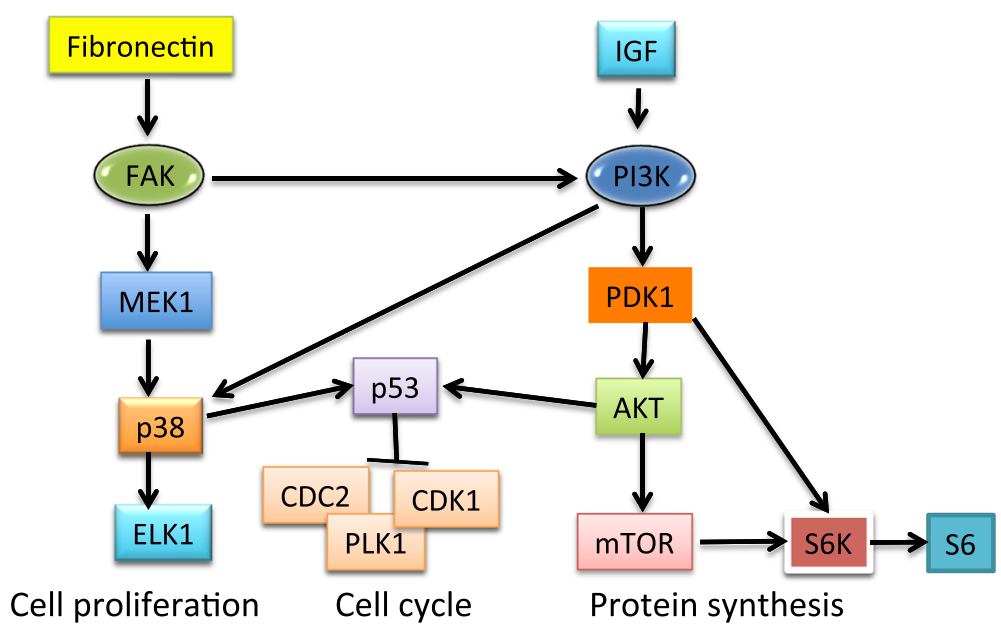

Fig. 5 Reverse-phase protein array analysis of RC-DHL cell line. a Supervised hierarchical clustering heatmap of 285 proteins demonstrating the differential protein expression profile of RC cells in comparison to three representative non-DHL-DLBCL cell lines, MZ, LP, and BJAB. b Schematic diagram showing the potential pathways activated in RC cells based on the RPPA analysis

primary $\mathrm{B}$ cell tumor at diagnosis. We believe that the newly characterized DHL cell line will provide useful in vitro and in vivo models for translational and biological studies related to human DHL, which is refractory to current therapy and urgently needs novel therapeutic approaches.

\section{Materials and methods}

\section{Cell culture}

The University of Texas MD Anderson Cancer Center Satellite Tissue Bank provided the patient samples used for these studies. With informed consent from the patient, the collected primary cells were purified from ascites by Ficoll centrifugation (Ficoll-Paque Plus; GE Healthcare, Life Sciences, Piscataway, NJ), washed in phosphate-buffered saline twice, and resuspended in RPMI 1640 (Life Technologies, Grand Island, NY) containing $15 \%$ heat-inactivated FBS, $2 \mathrm{mM}$ glutamine, and $50 \mu \mathrm{g} / \mathrm{mL}$ gentamycin at a concentration of $5-10 \times 10^{6}$ cells $/ \mathrm{mL}(40 \mathrm{~mL})$ in $75-\mathrm{cm}^{2}$ flasks. Cultures were maintained at $37{ }^{\circ} \mathrm{C}$ in a humidified incubator with a $5 \% \mathrm{CO}_{2}$ atmosphere. The medium was exchanged every 3-5 days depending on the cell growth rate. The cells were examined daily using an inverted microscope and counted weekly with a standard hemocytometer using trypan blue dye 


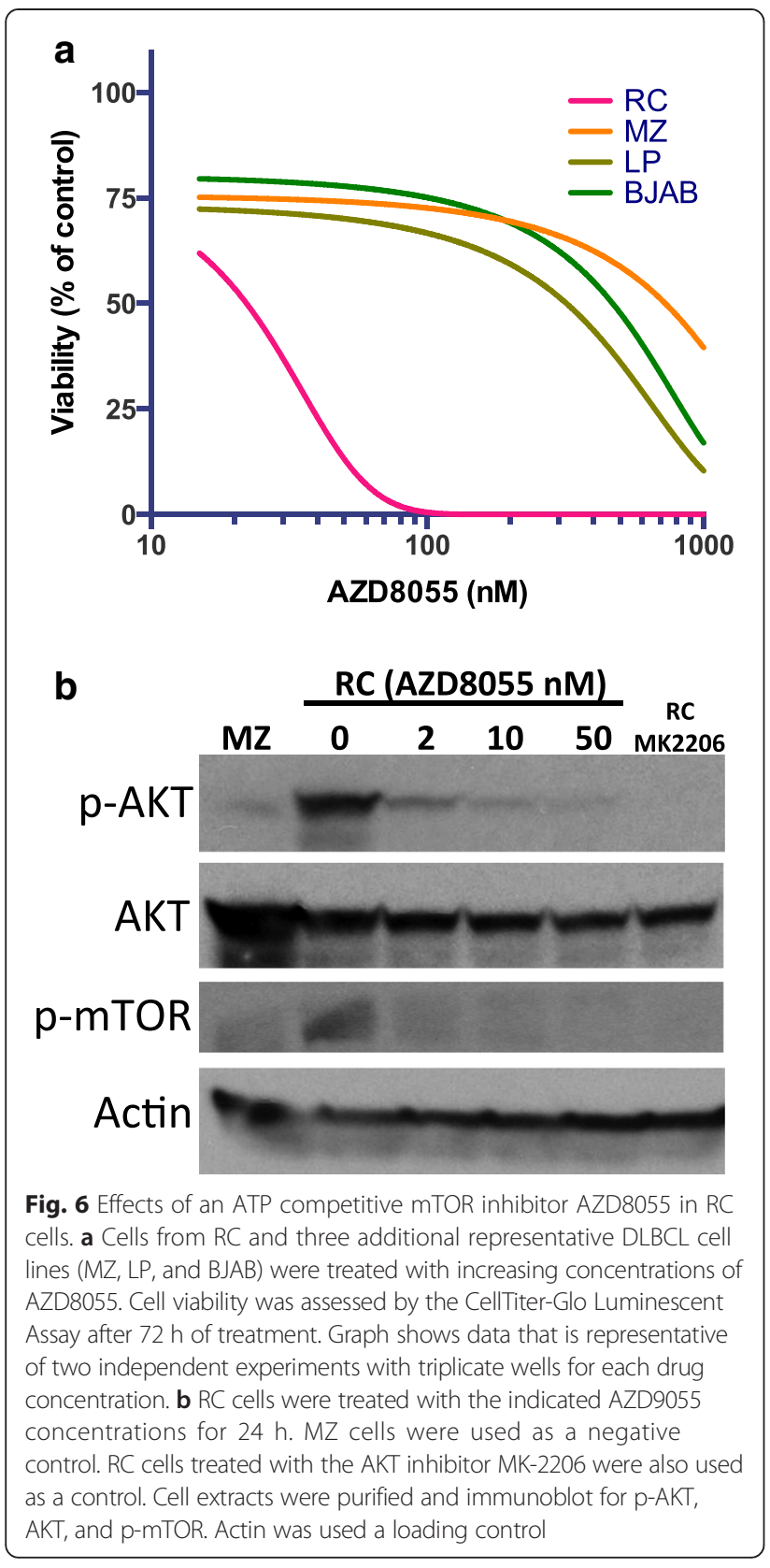

exclusion. No external growth factors or stimulatory cytokines were added during the establishment of the $\mathrm{RC}$ cell line.

\section{Cell growth and viability assay}

Cell viability was assessed using the CellTiter-Glo Luminescent Assay (Promega). Cells were plated in triplicates at $1-2 \times 10^{4}$ cells/well in 96-well plate with increase concentrations of AZD8055 (Selleckchem) in $100 \mu \mathrm{l}$ total volume. Cell viability was assessed at $72 \mathrm{~h}$ after treatment.

\section{Western blot analysis}

Cell lysates were prepared and immunoblotted as previously described $[29,30]$.

\section{Flow cytometry}

Eight-color flow cytometry analysis was performed with FACS Canto II instruments (BD Biosciences, San Jose, CA) using commercially available reagents on patient samples collected in ethylenediaminetetraacetic acid (EDTA) or cell line cells in culture medium. The cell population was gated using right-angle light scatter and CD45 expression. The panel of monoclonal antibodies used included those specific for CD3, CD4, CD5, CD8, CD10, CD11c, CD19, CD20, CD22, CD23, CD30, CD34 CD38, CD43, CD44, CD45, CD56, CD200, and surface kappa and lambda light chains. All antibodies were purchased from BD Biosciences. Data were analyzed using FCS Express software (De Novo Software, Los Angeles, CA). Antigen expression was scored as positive based on a significant shift in staining in comparison to a negative autofluorescence (empty channel) control.

\section{Conventional cytogenetic analysis}

RC cells were stimulated with phytohemagglutinin for $72 \mathrm{~h}$ before conventional G-banded karyotyping was performed with metaphase cells derived from tumor cell cultures. Briefly, metaphase cells were obtained after hypotonic treatment and fixation with 3:1 methanol-acetic acid solution using automatic harvesting system. Cell suspensions derived from the automatic harvesting system were dropped onto cleaned slides. G-banding was performed after the slides were dried at $60{ }^{\circ} \mathrm{C}$ overnight. Chromosome analysis and karyotyping, after the use of Genetix metaphase automatic scanning system, were performed with the CytoVision system. Twenty metaphases were fully analyzed as per standard protocols.

Fluorescence in situ hybridization (FISH) was performed on interphase nuclei from the cell culture using a dual-color, break apart $M Y C$ probe and IGH/BCL2 dual-color, dual-fusion translocation probes (Abbott Molecular, Des Plaines, IL), as described previously. The cutoff to define a positive result for rearrangement of $M Y C$, and $I G H / B C L 2$ probe is 3.8 and $0.1 \%$, respectively. A total of 200 interphase cells were analyzed.

\section{Short tandem repeat DNA fingerprinting}

Genomic DNA was isolated from the original tumor and the $\mathrm{RC}$ cell line using a Qiagen DNA purification kit (Valencia, CA). DNA fingerprinting of lymphoma cells was performed by the Institutional Characterized Cell Line core facility at MD Anderson using the STR method. Short tandem repeats are regions of microsatellite instability with defined tri- or tetra-nucleotide repeats that are located throughout the chromosomes. A 
PCR-based method using primers on non-repetitive flanking regions to generate PCR products of different sizes based on the number of repeats in the region was performed; the size of the products was determined by capillary electrophoresis. Extracted DNA was analyzed using the Power Plex 16HS System from Promega (Madison, WI). The relatedness of the original tumor and the RC cell line was determined by comparing the STR loci profiles of the respective samples.

\section{Epstein-Barr virus PCR amplification}

EBV genotyping was performed by PCR using genomic DNA to amplify a common region of the EBNA1 and $E B N A 2$ gene using a PCR kit from Promega with the following set of primers: EBNA1-F: GGT AGA AGG CCA TTT TTC CAC; EBNA1-R: CTC CAT CGT CAA AGC TGC AC; EBNA2-F: CAG GTA CAT GCC AAC AAC CTT; EBNA2-R: CCA ACA AAG ATT GTT AGT GGA AT. The PCR cycling conditions were as follows: $95{ }^{\circ} \mathrm{C}$ $2 \mathrm{~min}, 40$ cycles of $94{ }^{\circ} \mathrm{C} 1 \mathrm{~min}, 60^{\circ} \mathrm{C} 90 \mathrm{~s}, 72{ }^{\circ} \mathrm{C} 4 \mathrm{~min}$, followed by $72{ }^{\circ} \mathrm{C}$ for $10 \mathrm{~min}$ [31]. The EBV-negative Mino and the EBV-positive Granta mantle cell lymphoma cell lines were used as negative and positive controls, respectively.

\section{Xeno-transplant of RC cells in severed combined immunodeficient (SCID) mice}

All animal experiments were reviewed and approved by the MD Anderson Institutional Animal Care and Use Committee (IACUC). For in vivo studies, 6-week-old fe-

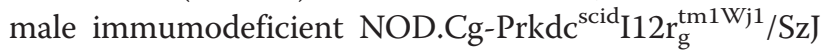
mice were purchased from Jackson Laboratories (Bar Harbor, ME) and housed under specific pathogen-free conditions at the SCID Mouse Barrier Facility at MD Anderson. RC cells $\left(10 \times 10^{6}\right)$ were injected intraperitoneally into the mice using a 27 -gauge needle.

\section{Reverse-phase protein array (RPPA)}

The RPPA Core Facility at MD Anderson Cancer Center performed the RPPA analysis and antibody validation [32]. For total protein lysate preparation, media were removed, and cells were washed twice with ice-cold phosphate-buffered saline (PBS) containing complete protease and PhosSTOPphosphatase inhibitor cocktail tablets (Roche Applied Science, Mannheim, Germany) and $1 \mathrm{mM} \mathrm{Na3VO4.} \mathrm{Lysis} \mathrm{buffer} \mathrm{(1 \%} \mathrm{Triton} \mathrm{X-100,} 50$ mMHEPES (pH 7.4), $150 \mathrm{mM} \mathrm{NaCl}, 1.5 \mathrm{mM} \mathrm{MgCl}$, $1 \mathrm{mM}$ EGTA, $100 \mathrm{mM} \mathrm{NaF}, 10 \mathrm{mM} \mathrm{NaPPi}, 10 \%$ glycerol, $1 \mathrm{mM}$ PMSF, $1 \mathrm{mM} \mathrm{Na3VO}$, and $10 \mu \mathrm{g} / \mathrm{mLa}-$ protinin). Samples were vortexed frequently on ice and then centrifuged. Protein lysates were adjusted to a $1 \mu \mathrm{g} /$ $\mu \mathrm{L}$ concentration, and a serial dilution of five concentrations was printed, with $10 \%$ of the samples replicated for quality control (2470 Arrayer; Aushon Biosystems) on nitrocellulose-coated slides (Grace Bio-Labs). Immunostaining was performed using a DakoCytomationcatalyzed system and diaminobenzidine colorimetric reaction. Slides were scanned on a flatbed scanner to produce 16-bit tiff images. Spot intensities were analyzed and quantified using Array-Pro Analyzer to generate spot signal intensities. Relative protein levels for each sample were determined by interpolation of each dilution curve from the "standard curve" constructed by a script in $\mathrm{R}$ written Bioinformatics. All the data points were normalized for protein loading and transformed to linear values that can be used for bar graph. Normalized linear value was transformed to $\log 2$ value, and then median-centered for hierarchical cluster analysis and for heatmap generation. The heatmap was generated in Cluster 3.0 (http://cluster2.software.informer.com/3.0/) as a hierarchical cluster using Pearson correlation and a center metric. The resulting heatmap was visualized in Treeview (http://rana.lbl.gov/EisenSoftware.htm) and presented as a high resolution .bmp format. Two hundred eighty-five unique antibodies and four secondary antibody negative controls were analyzed.

\section{Abbreviations \\ DHL: double-hit lymphoma; DLBCL: diffuse large B cell lymphoma; \\ EBV: Epstein-Barr virus; FBS: fetal bovine serum; FISH: fluorescence in situ hybridization; R-CHOP: rituximab immunotherapy and cyclophosphamide, doxorubicin, vincristine, and prednisone; RPPA: reverse-phase protein array; SCID: severe combined immunodeficiency.}

\section{Competing interests}

There are no conflicts of interest to disclose.

\section{Authors' contributions}

LVP and RJF were the principal investigators who directed all experiments. GL performed and analyzed and interpreted the conventional and molecular cytogenetic studies. ATT and JC performed cell culture, PCR, and immunoblots. LJM reviewed the morphologic findings. PC and JLJ performed and interpreted the results of flow cytometry immunophenotypic analysis. LVP, LJM, and RJF drafted the manuscript, which was read, edited, and approved by all authors.

\section{Acknowledgements}

We would like to thank the Bob Farahi Mantle Cell Lymphoma Fund for providing partial support for this study. STR DNA fingerprinting was performed by the Cancer Center Support Grant-funded Characterized Cell Line core. The University of Texas MD Anderson Cancer Center Satellite Tissue Bank was supported by the National Institutes of Health Lymphoma SPORE grant.

Received: 28 August 2015 Accepted: 13 October 2015

Published online: 29 October 2015

\section{References}

1. Alexander DD, Mink PJ, Adami HO, Chang ET, Cole P, Mandel JS, et al. The non-Hodgkin lymphomas: a review of the epidemiologic literature. Int J Cancer. 2007;120 Suppl 12:1-39. doi:10.1002/ijc.22719. PubMed PMID: 17405121

2. Johnson PW. Survival from non-Hodgkin lymphoma in England and Wales up to 2001. Br J Cancer. 2008;99 Suppl 1:S107-9. doi:10.1038/sj.bjc.6604606. PubMed PMID: 18813239; PubMed Central PMCID: PMC2557527.

3. Lossos IS. Molecular pathogenesis of diffuse large B-cell lymphoma. J Clin Oncol Off J Am Soc Clin Oncol. 2005;23(26):6351-7. doi:10.1200/ JCO.2005.05.012. PubMed PMID: 16155019. 
4. Morton LM, Wang SS, Devesa SS, Hartge P, Weisenburger DD, Linet MS. Lymphoma incidence patterns by WHO subtype in the United States, 1992-2001. Blood. 2006;107(1):265-76. doi:10.1182/blood-2005-06-2508. PubMed PMID: 16150940; PubMed Central PMCID: PMC1895348.

5. Bea S, Zettl A, Wright G, Salaverria I, Jehn P, Moreno V, et al. Diffuse large Bcell lymphoma subgroups have distinct genetic profiles that influence tumor biology and improve gene-expression-based survival prediction. Blood. 2005;106(9):3183-90. doi:10.1182/blood-2005-04-1399. PubMed PMID: 16046532; PubMed Central PMCID: PMC1895326.

6. Iqbal J, Greiner TC, Patel K, Dave BJ, Smith L, Ji J, et al. Distinctive patterns of BCL6 molecular alterations and their functional consequences in different subgroups of diffuse large B-cell lymphoma. Leukemia. 2007. PubMed PMID: 17625604

7. Oki Y, Noorani M, Lin P, Davis RE, Neelapu SS, Ma L, et al. Double hit lymphoma: the MD Anderson Cancer Center clinical experience. $\mathrm{Br} J$ Haematol. 2014;166(6):891-901. doi:10.1111/bjh.12982. PubMed PMID: 24943107

8. Ford RJ, Goodacre A, Ramirez I, Mehta SR, Cabanillas F. Establishment and characterization of human B-cell lymphoma cell lines using B-cell growth factor. Blood. 1990;75(6):1311-8. PubMed PMID: 2155676.

9. Goy A, Ramdas L, Remache YK, Gu J, Fayad L, Hayes KJ, et al. Establishment and characterization by gene expression profiling of a new diffuse large Bcell lymphoma cell line, EJ-1, carrying $t(14 ; 18)$ and $t(8 ; 14)$ translocations. Lab Invest. 2003;83(6):913-6. PubMed PMID: 12808126.

10. Hooper SD, Jiao X, Sundstrom E, Rehman FL, Tellgren-Roth C, Sjoblom T, et al. Sequence based analysis of U-2973, a cell line established from a doublehit B-cell lymphoma with concurrent MYC and BCL2 rearrangements. BMC Res Notes. 2012;5:648. doi:10.1186/1756-0500-5-648. PubMed PMID: 23171647; PubMed Central PMCID: PMC3534606.

11. Johnson-Farley N, Veliz J, Bhagavathi S, Bertino JR. ABT-199, a BH3 mimetic that specifically targets $\mathrm{BCl}-2$, enhances the antitumor activity of chemotherapy, bortezomib, and JQ1 in "double hit" lymphoma cells. Leuk Lymphoma. 2014:1-12. doi:10.3109/10428194.2014.981172. PubMed PMID: 25373508

12. Rahmani M, Aust MM, Benson EC, Wallace L, Friedberg J, Grant S. PI3K mTOR inhibition markedly potentiates HDAC inhibitor activity in NHL cells through BIM- and MCL-1-dependent mechanisms in vitro and in vivo. Clin Canc Res. 2014;20(18):4849-60. doi:10.1158/1078-0432.CCR-14-0034. PubMed PMID: 25070836; PubMed Central PMCID: PMC4166554.

13. Wu D, Wood BL, Dorer R, Fromm JR. "Double-hit" mature B-cell lymphomas show a common immunophenotype by flow cytometry that includes decreased CD20 expression. Am J Clin Pathol. 2010;134(2):258-65. doi:10.1309/AJCP7YLDTJPLCE5F. PubMed PMID: 20660329.

14. Maleki A, Seegmiller AC, Uddin N, Karandikar NJ, Chen W. Bright CD38 expression is an indicator of MYC rearrangement. Leuk Lymphoma. 2009:50(6):1054-7. doi:10.1080/10428190902930470. PubMed PMID: 19455464.

15. Li S, Lin P, Fayad LE, Lennon PA, Miranda RN, Yin CC, et al. B-cell lymphomas with MYC/8q24 rearrangements and IGH@BCL2/ $\mathrm{t}(14 ; 18)(\mathrm{q} 32 ; \mathrm{q} 21)$ : an aggressive disease with heterogeneous histology, germinal center B-cell immunophenotype and poor outcome. Mod Pathol. 2012;25(1):145-56. doi:10.1038/modpathol.2011.147. PubMed PMID: 22002575

16. Aukema SM, Siebert R, Schuuring E, van Imhoff GW, Kluin-Nelemans HC, Boerma EJ, et al. Double-hit B-cell lymphomas. Blood. 2011;117(8):2319-31. doi:10.1182/blood-2010-09-297879. PubMed PMID: 21119107.

17. Wang XJ, Medeiros LJ, Lin P, Yin CC, Hu S, Thompson MA, et al. MYC cytogenetic status correlates with expression and has prognostic significance in patients with MYC/BCL2 protein double-positive diffuse large B-cell lymphoma. Am J Surg Pathol. 2015. doi:10.1097/ PAS.0000000000000433. PubMed PMID: 25828389.

18. Thangavelu M, Olopade O, Beckman E, Vardiman JW, Larson RA, McKeithan TW, et al. Clinical, morphologic, and cytogenetic characteristics of patients with lymphoid malignancies characterized by both $t(14 ; 18)(q 32 ; q 21)$ and $\mathrm{t}(8 ; 14)(\mathrm{q} 24 ; \mathrm{q} 32)$ or $\mathrm{t}(8 ; 22)(\mathrm{q} 24 ; \mathrm{q} 11)$. Genes Chromosomes Cancer. 1990;2(2):147-58. PubMed PMID: 2278969

19. Macpherson N, Lesack D, Klasa R, Horsman D, Connors JM, Barnett M, et al. Small noncleaved, non-Burkitt's (Burkit-like) lymphoma: cytogenetics predict outcome and reflect clinical presentation. J Clin Oncol. 1999:17(5):1558-67. PubMed PMID: 10334544.
20. Kanungo A, Medeiros LJ, Abruzzo LV, Lin P. Lymphoid neoplasms associated with concurrent $\mathrm{t}(14 ; 18)$ and $8 \mathrm{q} 24 / \mathrm{c}-\mathrm{MYC}$ translocation generally have a poor prognosis. Mod Pathol. 2006;19(1):25-33. doi:10.1038/modpathol.3800500. PubMed PMID: 16258503.

21. Petrich AM, Gandhi M, Jovanovic B, Castillo JJ, Rajguru S, Yang DT, et al. Impact of induction regimen and stem cell transplantation on outcomes in double-hit lymphoma: a multicenter retrospective analysis. Blood. 2014;124(15):2354-61. doi:10.1182/blood-2014-05-578963. PubMed PMID: 25161267

22. Suresh T, Lee LX, Joshi J, Barta SK. New antibody approaches to lymphoma therapy. J Hematol Oncol. 2014;7:58. doi:10.1186/s13045-014-0058-4. PubMed PMID: 25355407; PubMed Central PMCID: PMC4172963.

23. Hagenbeek A, Gadeberg O, Johnson P, Pedersen LM, Walewski J, Hellmann $A$, et al. First clinical use of ofatumumab, a novel fully human anti-CD20 monoclonal antibody in relapsed or refractory follicular lymphoma: results of a phase 1/2 trial. Blood. 2008;111(12):5486-95. doi:10.1182/blood-200710-117671. PubMed PMID: 18390837.

24. Majchrzak A, Witkowska M, Smolewski P. Inhibition of the PI3K/Akt/mTOR signaling pathway in diffuse large B-cell lymphoma: current knowledge and clinical significance. Molecules. 2014;19(9):14304-15. doi:10.3390/ molecules190914304. PubMed PMID: 25215588.

25. Parikh K, Cang S, Sekhri A, Liu D. Selective inhibitors of nuclear export (SINE) — a novel class of anti-cancer agents. J Hematol Oncol. 2014;7:78. doi:10.1186/s13045-014-0078-0. PubMed PMID: 25316614; PubMed Central PMCID: PMC4200201.

26. Akinleye A, Avvaru P, Furgan M, Song Y, Liu D. Phosphatidylinositol 3-kinase (PI3K) inhibitors as cancer therapeutics. J Hematol Oncol. 2013;6(1):88. doi:10.1186/1756-8722-6-88. PubMed PMID: 24261963; PubMed Central PMCID: PMC3843585

27. Akinleye A, Chen Y, Mukhi N, Song Y, Liu D. Ibrutinib and novel BTK inhibitors in clinical development. J Hematol Oncol. 2013;6:59. doi:10.1186/ 1756-8722-6-59. PubMed PMID: 23958373; PubMed Central PMCID: PMC3751776.

28. Smith AD, Roda D, Yap TA. Strategies for modern biomarker and drug development in oncology. J Hematol Oncol. 2014;7(1):70. doi:10.1186/ s13045-014-0070-8. PubMed PMID: 25277503; PubMed Central PMCID: PMC4189730.

29. Pham LV, Fu L, Tamayo AT, Bueso-Ramos C, Drakos E, Vega F, et al. Constitutive BR3 receptor signaling in diffuse, large B-cell lymphomas stabilizes nuclear factor-kappaB-inducing kinase while activating both canonical and alternative nuclear factor-kappaB pathways. Blood. 2011;117(1):200-10. doi:10.1182/blood-2010-06-290437. PubMed PMID: 20889926; PubMed Central PMCID: PMC3037744

30. Pham LV, Tamayo AT, Yoshimura LC, Lo P, Ford RJ. Inhibition of constitutive NF-kappa B activation in mantle cell lymphoma B cells leads to induction of cell cycle arrest and apoptosis. J Immunol. 2003;171(1):88-95. PubMed PMID: 12816986.

31. Pham LV, Vang MT, Tamayo AT, Lu G, Challagundla P, Jorgensen JL, et al Involvement of tumor-associated macrophage activation in vitro during development of a novel mantle cell lymphoma cell line, PF-1, derived from a typical patient with relapsed disease. Leuk Lymphoma. 2015;56(1):186-93. doi:10.3109/10428194.2014.901511. PubMed PMID: 24611650.

32. Byers LA, Wang J, Nilsson MB, Fujimoto J, Saintigny P, Yordy J, et al. Proteomic profiling identifies dysregulated pathways in small cell lung cancer and novel therapeutic targets including PARP1. Canc Discov. 2012;2(9):798-811. doi:10.1158/2159-8290.CD-12-0112. PubMed PMID: 22961666; PubMed Central PMCID: PMC3567922 